\title{
What Makes Us Human (Homo sapiens)? The Challenge of Cognitive Cross-Species Comparison
}

\author{
Christophe Boesch \\ Max Planck Institute of Evolutionary Anthropology
}

\begin{abstract}
Two major theoretical approaches have dominated the quest for uniquely human cognitive abilities: a developmentalist approach stressing the importance of environmental and social conditions, and a predominant approach in experimental and comparative psychology, the deterministic approach suggesting the effect of environmental and social conditions to be minimal. As a consequence, most claims of human cognitive uniqueness are based on comparisons of White middle class Westerner humans (Homo sapiens) with captive chimpanzees (Pan troglodytes). However, humans are much more than only White middle class Westerners, and chimpanzees are much more than only captives. A review of some data available on different populations of humans and chimpanzees reveals that only the predictions of the developmentalist approach are supported. In addition, systematic biases are too often introduced in experiment protocols when comparing humans with apes that further cast doubts on cross-species comparisons. The author argues that only with consideration of within-species population differences in the cognitive domains and the use of well-matched cross-species experimental procedures will an objective understanding of the different cognitive abilities between species emerge. This will require a shift in the theoretical approach adopted by many in experimental and comparative psychology.
\end{abstract}

Keywords: human, chimpanzee, comparison, within-species variation, cognition

Humans (Homo sapiens) have always been interested in "what makes us human" and "what distinguishes us from other animal species." In all traditional societies, myths have been proposed that provide scenarios as to how humans came to be and of a possible relationship with other animals. Religion and science have zealously taken up the challenge and have come up with their own propositions. Originally, most scientific propositions about human origin did not rely on observations from other species, simply because information on these species was not available. For example, culture was proposed in the early 1930 s to be a uniquely human ability before any relevant data on different animal populations were available (Barnard, 2000; Kuper, 1999). Similarly, claims about uniquely human abilities to use and make tools were proposed in the late 1880 s, well before observations on wild primate populations (Bowler, 1989; Darwin, 1859).

Since the early 1960s, field observations on the natural behavior of many animals have been conducted, finally enabling scientists to consider the abilities of nonhuman species when contemplating "what makes us human." In vast fields of science, this opportunity

Financial support for this article was provided by the Max Planck Society. I would like to thank especially Brutus, Salomé, and Frodo for tolerating my presence and opening my eyes to the complexity of population differences and the role of environment in chimpanzees. I am very grateful to the Ivorian and Tanzanian authorities for allowing me to work in the Taï National Park and the Gombe Stream National Park; many thanks to Hedwige Boesch, Brian Hare, Mimi Arandjelovic, Yasmin Moebius, Tara Stoinski, and Linda Vigilant for comments on earlier versions of this article.

Correspondence concerning this article should be addressed to Christophe Boesch, Max Planck Institute of Evolutionary Anthropology, Deutscher Platz 6, 04 103, Leipzig, Germany. E-mail: boesch@eva.mpg.de has been seized and has led to the upsurge of behavioral ecology as well as to the emergence of new fields, such as biological anthropology, and comparative and evolutionary psychology. The inclusion of animal models was decisive about reframing models of human evolution within modern evolutionary theory thinking of adaptation and fitness benefits (Jolly, 1999; Maynard Smith, 1982; Trivers, 1971; Wilson, 1975). However, researchers have to acknowledge that this is still an ongoing process and that although some research disciplines have welcomed such new information, others have been slow or inconsistent at including field data.

Moreover, a new debate concerning the shortcomings and benefits of observational data has led to a resurgence of interest in captive studies as the main source for understanding cognitive capacities in animals. On the one side, some have argued that field data are just anecdotes and are therefore of a limited scientific value, as only experiments allow to control for the influence of possible different confounding factors (Bernstein, 1988; Hauser, 2000; Heyes, 1998; Povinelli, 1996, 2000; Tomasello \& Call, 1997), whereas others argued that because of the logistic difficulties of fieldwork, key observations needed to explain observed patterns might always be missed (de Waal, 1982). On the other side of the debate, most argue that animals have evolved behavioral and cognitive traits, over hundreds of generations, needed to survive and thrive, and that animals should be studied under natural conditions if one wants to understand the full capacities of those animals (Boesch, 1993; Byrne, 1995; Cheney \& Seyfarth, 1990; McGrew, 1992). Furthermore, captive living conditions are impoverished compared with natural ones, and therefore the development of abilities during ontogeny might be negatively affected (Boesch, 1993; Whiten, 2000). The debate on the relative importance of field observations versus controlled captive experiments, to my mind, find its roots in a striking disagreement on the 
theoretical approaches to the development of behavioral and cognitive capacities in individuals that needs to be clearly spelled out if researchers want to bring some clarity in this debate. Two key questions follow: Are differences in cognitive capacities observed between populations within a species? Do differences in the living conditions experienced during ontogeny affect the development of cognitive abilities?

Here, I first formulate the two different theoretical approaches that underlie the different positions that have been taken to address these questions and show how divergent the predictions of these approaches are. Next, I review some of the available data about cognitive differences between populations within both humans and chimpanzees (Pan troglodytes) to test the support for the different predictions, and finally I make some propositions as to how the understanding of species differences in the cognitive domain may be improved.

\section{Two Different Theoretical Approaches}

\section{Developmentalist Approach}

Modern evolutionary biology has shown that individuals inherit a genotype from their ancestors that interacts with the environment throughout the life of the individual to produce a full grown individual (e.g., Dawkins, 1986; Ridley, 1996; Stearns \& Hoekstra, 2000). This genotype is already the product of the selection process faced by many generations and reflects the interactions with past environmental conditions. This approach postulates a constant interaction of the genetic make-up with the environmental conditions that may result in quite a range of outcomes (e.g., Cole, 2006; Geary, 2005; Laland \& Janik, 2006; West-Eberhard, 2003; Williams, 1966; Wilson, 1975). So, each individual's abilities result from an interaction between history and experience.

Developmental biologists have amply demonstrated the importance of such interactions on morphological and behavioral traits in many species (e.g., Atkinson \& Thorndyke, 2001; Wagner, Chiu, \& Laubichler, 2000; West-Eberhard, 2003). The most dramatic cases include examples of fruit flies that are genetically identical but differ in many life history traits-such as age of first reproduction, number of eggs produced, and flying behavior-as a result of experiencing different living conditions during development (Stearns, 1992; Stearns \& Hoekstra, 2000). This has been labeled developmental reaction norms and has been shown to be a general phenomenon. A predominant interest in the field of behavioral ecology is observing and explaining the variability of the social organization, foraging behavior and reproductive strategies of numerous species observed under varying ecological conditions (Alcock, 1989; Krebs \& Davies, 1993; Wilson, 1975). It has become clear that the degree of diversity observed within species varies considerably and that such variation increases with learning abilities. Behavioral flexibility, measured by foraging innovation, social learning, and tool use, has been shown to increase, both in birds and in primates, with brain size (Lefebvre, Nicolakakis, \& Boire, 2002; Lefebvre, Whittle, Lascaris, \& Finkelstein, 1997; Reader \& Laland, 2002).

So the question is whether such intraspecific variability also exists in cognitive domains. The theory of natural selection predicts that individuals will adapt to different environmental conditions to survive and be able to reproduce. Different precise pre- dictions can be formulated: First, the more diverse the environmental conditions faced by an animal species, the more variation will be expected in the cognitive domain between populations of that species. Altitude and latitude affect climatic parameters that will determine the amount, type, and distribution of food sources, which in turn influence individual foraging strategies that require cognitive abilities in terms of orientation, mapping, causality understanding, and predicting. Foraging strategies will, in turn, affect the social structure, social group size, and social interactions that are the foundation of all social cognition abilities. Therefore, researchers predict that species with a larger distribution on the planet will present more variability in behavioral traits and cognitive abilities. Humans, with a much wider distribution on Earth than chimpanzees, are predicted to show more withinspecies variation in cognitive abilities than chimpanzees.

Second, different cognitive abilities are predicted to develop in a flexible way depending on the conditions experienced during ontogeny, and this will be more apparent in large brained species that have been shown to possess more learning abilities (Lefebvre et al., 2002; Reader \& Laland, 2002). This will provide individuals with a flexible response allowing them to survive under more diverse conditions. A third prediction is that variation in cognitive abilities is expected to increase with greater niche differentiation within social groups. High within-group competition will result in certain classes of individuals (e.g., subadult, female, or lowranking individuals) facing different environmental conditions than other classes, and this will lead to the development of different cognitive abilities. For example, low-ranking peripheral females in hamadryas baboon groups have been shown to explore and find more hidden food than high-ranking females (Sigg, 1980). Classic examples of this in noncognitive domains are (a) that low-ranking female baboons suppress reproduction totally during low food availability years, whereas high-ranking ones continue to reproduce normally (Altmann, 1980) or (b) that high-ranking female red deer produce more sons than do low-ranking females (Clutton-Brock, Albon, \& Guiness, 1984).

In summary, under a developmentalist approach, cognitive development is predicted to be influenced by living conditions, and important intraspecific variation between populations is expected as a result of varied living conditions.

\section{Deterministic Approach}

René Descartes postulated a fundamental difference between humans and animals, whereby he described humans as thinking animals but all other animals as machines following a prefixed program (Descartes, 1964-1973, in Bowler, 1989, p. 57). In other words, humans are born resembling a white sheet upon which everything can be written, whereas animals are genetically rigidly fixed. Under this approach, humans are proposed to be only influenced by experience, and animals only by history. Such a classic view has been held in social sciences and has been only challenged by the emergence of modern evolution theory. Its influence can be strongly seen in some circles of cultural and social anthropology (Barnard, 2000; Kuper, 1999).

Most striking is its prevalence in the field of psychology. This deterministic approach predicts that individuals' cognitive abilities are not influenced by experiences during development and that individuals develop full-fledged species-specific cognitive abilities 
under a whole array of different environmental conditions. The main manifestation of this approach in psychology has been the general consensus that animal captive studies are fully representative of the cognitive abilities of the species as a whole. Throughout the recent literature, data collected with captive animals are presented as representing species-typical traits, without much discussions of the possible effect of experience on the cognitive abilities (e.g., Call, Carpenter, \& Tomasello, 2005; Call \& Tomasello, 1996; Galef, 1988, 1990; Heyes, 1993, 1994, 1998; Povinelli, 1994, 1996, 1999, 2000; Povinelli \& Vonk, 2003; Premack \& Premack, 1983; Tomasello, 1996, 1998, 1999; Tomasello, Carpenter, Call, Behne, \& Moll, 2005; Tomasello, Kruger, \& Ratner, 1993). This is especially puzzling as earlier workers assembled conclusive data demonstrating the negative impacts of captive conditions on the development of different cognitive abilities in primates (Davenport, 1979; Gallup, McClure, Hill, \& Bundy, 1971; Harlow \& Harlow, 1962, 1965; Harlow, Harlow, \& Suomi, 1971; Hinde, 1971; Mason, 1965, 1978; Menzel, Davenport, \& Rogers, 1961, 1970; Rogers \& Davenport, 1969). Only few psychologists have kept to these pioneers in considering the possible impact of captive conditions and tried to address them while preserving the advantage of experiments that allow controlling for the influence of confounding variables (Byrne, 1995; de Waal, 2001; B. T. Gardner \& Gardner, 1989; R. Gardner, 2005; Whiten, 2000). For example, one innovative Japanese group has pioneered the establishment of long-term triadic relationships between a mother chimpanzee, her infant, and a human tester followed by subsequent introduction of a unique face-to-face testing procedure (Imura, Tomonaga, \& Yagi, 2006; Matsuzawa, 2006; Murai, 2006).

Regarding experimental psychology studies on humans, a strict deterministic approach seems, paradoxically, to have been developing for human studies, which is quite in opposition with what Descartes originally proposed. Indeed, researchers have collected a majority of experimental psychology data using White middleupper class Westerners, and, despite the fact that this represents only a small minority of the societies present in humans, has generally been considered as representative for all humans, without preliminary testing of whether this generous assumption was true (see, e.g., Meltzoff, 1996; Piaget, 1935, 1945; Piaget \& Inhelder, 1947; Tomasello, 1999; Wellman, Cross, \& Watson, 2001). This approach seems surprising considering that historically, humans have been proposed to be so much more flexible than animals, and I hope that by making clear the assumption underlining the deterministic approach as applied to humans, some debates about it will emerge. The prediction of the deterministic view that individual experience does not count in human cognition needs to be tested.

Within the field of psychology, it is mainly cultural psychologists that have challenged this occidental-biased approach to human cognition (Berry, Poortinga, Segall, \& Dasen, 2002; Dasen, Inhelder, Lavallée, \& Reitschitzki, 1978; Dasen \& Mishra, 2000; Haun, Rapold, Call, Janzen, \& Levinson, 2006; Majid, Bowerman, Kita, Haun, \& Levinson, 2004; Murray, 1999; Segall, Dasen, Berry, \& Poortinga, 1999), but their contributions still need to be considered seriously by the experimental psychologists. At the same time, social psychologists have also invested a lot of time to demonstrate how socioecological conditions affect the development of cognitive capacities in humans (e.g., Carpendale \& Lewis,
2004; Correa-Chavez \& Rogoff, 2005; Holmes, Black, \& Miller, 1996; Rogoff, 1990), and their contributions are important to balance the predominant importance given to data coming from White middle-upper class Westerners. On the other side, evolutionary thinking has been taken to an extreme by some in the field of evolutionary psychology, who are championing a strict deterministic approach to human cognition suggesting that history is determinant and experience counts only as a trigger leading to the full expression of particular genetically fixed cognitive modules (Evans, 2003; Sperber \& Hirschfeld, 2004; Tooby \& Cosmides, 1988).

The predictions about the respective roles of history and experience emerging from the developmentalist and deterministic approaches are quite different, making it possible to consider whether the data support either approach. More specific, if within-species variation in cognitive abilities is present in humans, then researchers need to reevaluate their conclusions about human cognitive abilities and redirect research efforts toward studying cognitive abilities in humans living under different cultural and environmental conditions. Furthermore, if this is also true for other animals, then most results in comparative psychology will need reconsideration, and much more care should be taken in making comparisons between species in the cognitive domain.

\section{Do Population Differences Exist in Cognitive Domains in Humans?}

As cross-cultural psychology is still in its infancy, only a limited number of human societies have been studied, and researchers are still far from being able to document the whole of human cognitive variability. Nevertheless, the data available in some cognitive domains will allow researchers to test the different predictions about population differences in cognition. I focus upon data for two specific domains in which the largest set of comparative data is available, the notion of space and the understanding of others, often also called theory of mind.

\section{Notion of Space in Humans}

Two ways to address the notion of space have been identified; the first, following Jean Piaget, has been to look at the emergence of a topographic or a Euclidean notion of space during an individual's development (Piaget \& Inhelder, 1947) (see Table 1). In White middle class Westerners (WMCs), a topographic space, based mainly on landmarks that are related to one another, emerges first by some 5 years of age and is later replaced by a more elaborate Euclidean space, in which coordinates are used to relate landmarks allowing to use shortcuts and measure distances between objects by the age of 10 years. In cross-cultural studies, a similar sequence of appearance has been confirmed in some cultures, although the age of emergence might be quite different (Segall et al., 1999). Hunter-gatherers, like the Inuit or the Aborigines, seem to acquire a Euclidean space systematically and quite early, whereas traditional farmers, like the Ebrié, are much slower in the acquisition of a full notion of space, and a large proportion of individuals do not seem to acquire a Euclidean notion at all (Dasen, 1982; Segall et al., 1999). It is interesting that sex differences have also been found in such a domain, with 
Table 1

Comparisons of Some Spatial Notions in Use in Different Human Societies

\begin{tabular}{lll}
\hline \multicolumn{1}{c}{ Cultural group } & \multicolumn{1}{c}{ Performance } & \multicolumn{1}{c}{ Reference } \\
\hline WMC & Topographic + Euclidean & Piaget \& Inhelder, 1947 \\
Inuit (Greenland) & Topographic + Euclidean & Dasen, 1982 \\
Aborigines (Australia) & Topographic + Euclidean & Dasen, 1982 \\
Ebrié (Côte d'Ivoire) & Topographic only & Dasen, 1982 \\
WMC & Relative before absolute & Piaget \& Inhelder, 1947 \\
Vranisi (India) & Relative and absolute & Mishra et al., 2003 \\
Tzelta (Mexico) & Absolute before relative & Brown \& Levinson, 2000 \\
Tzotzil (Mexico) & Absolute before relative & De León, 1994 \\
Bali (Indonesia) & Absolute before relative & Wassmann \& Dasen, 1998 \\
Roopchandpur (India) & Absolute before relative & Mishra et al., 2003 \\
Bhimeshwor (Nepal) & Absolute before relative & Mishra et al., 2003 \\
Haillom (Namibia) & Absolute before relative & Haun, Rapold, et al., 2006 \\
Guugu Yimithirr (Australia) & Absolute only & Majid et al., 2004 \\
\hline
\end{tabular}

Note. $\quad \mathrm{WMC}=$ White middle class Westerner.

women having less spatial but more numerical abilities than men (Dasen, 1982).

Another way to look at the notion of space is to focus on the way individuals place objects in space (Levinson, Kita, Haun, \& Rasch, 2002; Majid et al., 2004), as objects can be placed in relation to others (e.g., to the left or right), producing a so-called "relative" notion of space, or objects can be placed in absolute terms (e.g., in the north), following an "absolute" notion of space. In the WMCs, a relative notion emerges first, and even if an absolute one emerges later, the former will remain the main one used (Levinson et al., 2002). This sequence of emergence has been confirmed in some cultures, whereas in others a reversal has been observed whereby the absolute notion emerges first and remains the one used in most situations (see Table 1). In one case, the absolute is the only one present. Contrary to what has been observed in Westerners, studies on two groups of Mayans, the Tzotzil and the Tzeltal, have revealed that they mainly use an absolute concept of space that they acquire remarkably early in life (Brown \& Levinson, 2000; De León, 1994). The Tzeltal living in southern Mexico have a distinct linguistic repertoire for talking about spatial relations that is based on an absolute notion of space in which, for example, objects are placed up or down hill rather than left or right. Mayan children develop an absolute notion of space before a relative one, in contrast to what is observed in the occidental world. Balinese spatial orientation is even more absolute than that observed in the Maya, as Balinese space is directed toward the highest mountain of the island, Mont Agung, culminating at 1,800 $\mathrm{m}$ at the center of the island (Wassmann \& Dasen, 1998). However, absolute directions point toward different cardinal directions in different villages, as each village is located at a distinct point around the mountain on this circular island's seashore. Furthermore, villages that have been established by migrants use their original village as the point of origin for determining the direction of the mountain. Such an extreme absolute notion of space forces men of different villages to agree beforehand on the bearing of each direction when playing a game based on orientation notions. Here, as in the Mayan case, it seems that the development of spatial knowledge is the converse of the occidental scenario.

\section{Understanding of Others in Humans}

The ability to understand others as independent agents with their own knowledge and beliefs (i.e., theory of mind) has become a contentious topic of research because it intersects with the quest to understand differences between humans and chimpanzees. Some suggest it exists in chimpanzees (Premack \& Woodruff, 1978), whereas many others propose it as a hallmark of humanity (Astington \& Baird, 2004; Carruthers \& Smith, 1996; Gopnik \& Meltzoff, 1994; Hala \& Chandler, 1996; Leslie, Friedman, \& German, 2004; Meltzoff, 1995; Povinelli, 1996; Povinelli \& Vonk, 2003; Tomasello, 1999; Tomasello et al., 2005; Tomasello et al., 1993; Wellman et al., 2001; Wimmer, Hogrefe, \& Perner, 1988). I focus for comparison purposes on only one theory of mind test, the false-belief test, as it has by far been used the most frequently (see Table 2). The false-belief test requires the subject to predict where a third person will predict an object is hidden when that object location has been changed while only the subject was present. Typically, the majority of WMCs pass this test by the age of 4 years (Wellman et al., 2001). As can be seen from Table 2, similar development paths have been confirmed in some other populations in which children attend city schools. In other human populations, the time of successful understanding of the falsebelief test can be markedly delayed to the point of not being observed in older children. More studies will be needed to know whether those noted as "absent" in Table 2 would remain so after older individuals were tested.

The frequent use of the false belief test allows researchers to test whether different childhood environments met by individuals within a same population affect the development of this cognitive ability (see Table 3). For example, within the United States, a study of people with low income, composed primarily of African American families, revealed that despite an improvement with age in false-belief tasks, they generally fell short of the level of performance reported from White middle class individuals; $37 \%$ passed the test by age 4 versus $61 \%$ in WMC samples, and $57 \%$ of the 5-year-olds were successful compared with $89 \%$ in the WMC samples (Holmes et al., 1996). Similar studies conducted with low income families, comprising mainly Caucasian subjects, in Oregon 
Table 2

Comparison of the Ages at Which Individuals From Different Cultures Develop an

Understanding of Others, on the Basis of Results of the False-Belief Test

\begin{tabular}{lll}
\hline \multicolumn{1}{c}{ Cultural group } & Performance & \multicolumn{1}{c}{ Reference } \\
\hline WMC & Present by 4 years & Wellman \& Watson, 2001 \\
Baka (Cameroon) & Present by 4 years & Avis \& Harris, 1991 \\
City school (Peru) & Present by 5 years & Callaghan et al., 2005 \\
City school (India) & Present by 5 years & Callaghan et al., 2005 \\
City school (Thailand) & Present by 5 years & Callaghan et al., 2005 \\
Tolai (Papua New Guinea) & Present by 7 years & Vinden, 1999 \\
Yukatek (Mexico) & Present by 7 years & Knight et al., 2004 \\
Mofu (Cameroon) & Present by 9 years & Vinden, 1999 \\
Village school (Samoa) & Absent at 5 years & Callaghan et al., 2005 \\
Junin Quechua (Peru) & Absent at 5 years & Vinden, 1996 \\
Tainae (Papua New Guinea) & Absent at 14 years & Vinden, 1999 \\
\hline
\end{tabular}

Note. Presented are the ages at which the majority of individuals have been observed to succeed in the test. For the cases in which the individuals did not succeed, the oldest ages tested are listed. WMC $=$ White middle class Westerner.

(Pears \& Moses, 2003) and in London (Cutting \& Dunn, 1999) have confirmed these results.

To further stress the importance of the environment experienced during childhood, Perner, Ruffman, and Leekam (1994) showed that besides family income, family composition revealed itself as well to be a major influence on false-belief test performance, as the number of siblings a child has positively affects the emergence of the understanding of others. After careful analysis, it was shown that it is the presence of older siblings, and not younger ones, that has this decisive effect (Ruffman, Perner, Naito, Parkin, \& Clements, 1998). The more older siblings that are present, the earlier an understanding of others emerges, so that 4-year-old children with two older siblings are 2.4 times more accurate than those with younger or no siblings (see Table 3). Additionally, the quality of interactions within the family was also shown to accelerate the emergence of this ability, with mental stimulations by mothers and friendly relationships between family members having positive effects (Howe, Petrakos, \& Rinaldi, 1998; Howe, Rinaldi, Jennings, \& Petrakos, 2002; Slomkowski \& Dunn, 1996).

This review of some experimental data on two cognitive abilities reveals that important differences between human populations emerge as a function of the living conditions faced during early life. This strongly contradicts the deterministic approach but is in line with the predictions of the developmentalist one.

Similar conclusions have also been reached concerning other cognitive domains. For example, naïve or folk biology has been proposed to be implicitly universal, as all people around the world need to be able to understand and predict the general properties of the objects around them. In an attempt to document this, researchers compared standard U.S. undergraduates (equivalent to the WMC group) with Itza Maya elders from Guatemala, and U.S. Ph.D. holders in botany, middle class children near U.S. universities, and Yutatek Mayans in rural Mexico (Atran, Medin, \& Ross, 2005; Medin \& Atran, 2004; Ross, Medin, Coley, \& Atran, 2002). Most of these groups have the tendency to categorize objects and use them to think about biology, but their ways of categorizing animals and plants are strongly affected by experience. U.S. children in contact with nature possess more similarities with Maya elders without any formal education than with U.S. undergraduates. It is interesting that the researchers found that on most of the tasks, the U.S. undergraduate group failed to match the results of the other human groups. The authors accordingly suggested that U.S. undergraduates are atypical and that contemporary people in small-scale societies that continue to live intimately with

Table 3

Comparison of the Effect of Socioeconomic Conditions on the Emergence of an Understanding of Others in Humans

\begin{tabular}{llll}
\hline Human group & \multicolumn{1}{c}{ Factor } & Influence & \multicolumn{1}{c}{ Reference } \\
\hline Head Start & Low income & $37 \%$ later & Holmes et al., 1996 \\
London & Low income & $20 \%$ later & Cutting \& Dunn, 1999 \\
WMC & No. of siblings & Positive effect & Perner et al., 1994 \\
WMC & No. older siblings & 2.4 times earlier & Ruffman et al., 1998 \\
WMC & Social status & Negative effect & Rutherford, 2004 \\
WMC & Dominance & Negative effect & Thomas et al., 1972 \\
WMC & Maternal style & Positive effect & Pears \& Moses, 2003 \\
WMC & Relation quality & Positive effect & Howe et al., 2002 \\
\hline
\end{tabular}

Note. Under "Influence" are presented the delay or acceleration in the performance compared with the WMC performance (positive effect/negative effect $=$ performance accelerates/delays as the factor increases). WMC $=$ White middle class Westerner. 
nature are more representative of humanity (Medin \& Atran, 2004). Similarly, large differences in causal reasoning between East Asians and Westerners (represented by Americans, Canadians, and Europeans) have been documented (Choi, Nisbett, \& Norenzayan, 1999; Nisbett, Peng, Choi, \& Norenzayan, 2001; Norenzayan \& Nisbett, 2000; Norenzayan, Smith, Kim, \& Nisbett, 2002). To summarize, East Asians use a holistic approach that takes into account the situations and constraints of an object and assigning causality to it, making relatively little use of categories or formal thinking, whereas Westerners are more analytical, primarily paying attention to the object and the categories to which it belongs while using rules to understand its behavior (Nisbett et al., 2001). The result is that East Asians_-including Korean, Japanese, and Chinese people_-judge causality in quite different ways and disagree on many judgments with U.S. White middle class subjects. This large difference has been proposed to be already apparent in the way that classical philosophy and science has been done in the past (Nisbett et al., 2001).

Also noteworthy is that counting abilities seem to be affected by the socioeconomic environment. For example, the Oksapmin of Papua New Guinea are famous for counting by employing names of body parts (e.g., 1 is the thumb of the right hand, 12 is the right ear, or 23 is the thumb of the left hand; Saxe, 1981, 1982; Saxe \& Moylan, 1982). Such a system works only for a limited number of items, and addition problems - including more than 27 objectsare unsolvable. Oksapmin traditionally do not count with objects they do not see, and no representational solution exists in the absence of objects. This counting system progressively gave way to numerical conventions similar to the Western ones starting in 1961 when missionaries and government officers introduced the first money and trade shops (Saxe \& Esmonde, 2004, 2005). Similarly, Bantu language in Africa contains only five words for numbers, and the Zulu language in South Africa has numbers referring only to finger gestures (Zaslavsky, 1973), whereas Munduruku and the Pirahã languages in the Amazonia that lack words for numbers beyond five, fail in exact arithmetic with numbers larger than five (Gordon, 2004; Pica, Lemer, Izard, \& Dehaene, 2004). In Africa as well, the introduction of coins and shops has led to a shift of counting by using more numericals (Saxe \& Esmonde, 2005; Zaslavsky, 1973). A recent study comparing native Chinese and English speakers dramatically illustrates how differences in experience faced during the ontogeny can lead to remarkable alteration in brain function during mathematical problem solving (Cantlon \& Brannon, 2007; Tang et al., 2006).

To conclude, despite the fact that the data are preliminary and represent only a small subset of the human population diversity, the trend is clear in showing that large differences in cognitive domains exist between human populations and that the environmental conditions they face affect their performances. Therefore, the assumption that WMC subjects are representative of all humans is strongly contradicted. This represents a challenge for the understanding of human cognition, as researchers need to take in account the breadth of diversity of performance present in humans rather than restrict themselves to the performance of a single population. In addition, it is important to understand which factors of the environment affect the development of specific cognitive abilities (as can be seen in Table 3).

Diversity in human cognitive performance represents a great challenge to a deterministic approach in comparative psychology and may have major consequences for the way researchers try to answer the question of "what makes us human." The inclusion of all possible human cognitive development pathways will question most present claims about human cognitive uniqueness. For example, the ability to understand others emerges in WMC humans by the age of 4 years. Relying on that age, researchers have done all comparisons on this ability with chimpanzees or other apes using young subadult individuals. If, however, the emergence of this ability can happen in normal humans much later, as documented in Table 2, it follows that researchers also need to allow for possible later maturation of this ability in apes before drawing any conclusions about species differences. Similarly, family size and composition plays a significant role on the time of emergence of this ability in humans (see Table 3). Given the very close proximity of apes to humans, it is parsimonious to admit that such factors likely also play some role in apes. So, comparisons with apes should only include individuals that have grown up in complete families with older siblings, and data collected with individuals that have grown up under socially deprived captive conditions should be discarded. A similar variability has been observed for the notion of space in which an absolute notion seems to be mastered by children between 4 and 7 years, whereas a relative notion is mastered only at an age of about 11 years (Haun, Rapold, et al., 2006). Cross-species comparisons need to take into account such possible large time delays in maturation in a notion of space.

\section{Do Population Differences in Cognitive Domains Exist in Chimpanzees?}

If cross-cultural studies in humans are in their infancy, the study of differences between populations in chimpanzees is even less developed. Only 11 populations have been studied with enough detail to permit a preliminary listing of potential cultural differences in that species (Whiten et al., 1999). In addition, the general acceptance of captive studies as representative for the ability of an animal species has strongly discouraged cognitive studies with wild populations.

From a deterministic point of view this is not a problem, as population differences in cognitive abilities are expected to be negligible, and captive populations of chimpanzees would be considered as the most appropriate study individuals. This approach considers chimpanzee cognitive development as not affected by experience and context and assumes that they "act merely as slavish vehicles of the genes" (Evans, 2003, p. 458). From a developmentalist standpoint, in contrary, the development of cognitive abilities is predicted to be dependent upon the conditions faced during the upbringing. Thus, captive chimpanzees would possess cognitive abilities reflecting their captive living conditions, and these abilities are predicted to be quite different from those required to survive and be able to reproduce in the wild. This does not challenge the fact that captive studies in chimpanzees have been instrumental in revealing some major facets of their cognition, such as self-recognition (Gallup, 1970), symbolic abilities (B. T. Gardner \& Gardner, 1989; Savage-Rumbaugh, Rumbaugh, \& Boysen, 1980), theory of mind (Premack \& Woodruff, 1978), and some aspects of their social strategies (de Waal, 1982). Indeed, such captive studies can be very important for the understanding of the evolution of cognitive abilities. 
Thus, the central question is whether the conditions of a chimpanzee's upbringing affect its cognitive abilities. Direct evidence is fairly limited and mainly restricted to studies comparing captive chimpanzees living in socially and environmentally deprived situations with those experiencing enriched social and environmental conditions (with many objects and daily interactions with conspecifics or human caretakers). Such social and physical enrichment remarkably improves the primate's performance on different problem-solving and social-learning tasks (Davenport, 1979; Harlow et al., 1971; Mason, 1978; Menzel et al., 1961; Rogers \& Davenport, 1969; Savage-Rumbaugh, Rumbaugh, \& Boysen, 1978). In a precise study comparing lab-reared chimpanzees with cross-fostered and wild ones, B. T. Gardner and Gardner (1989) showed that the rearing environment differences between the three groups led to large differences in the time of emergence in many positional and locomotory behaviors. It is interesting that the enriched captive conditions faced by cross-fostered chimpanzees were very favorable, and their development was in many ways similar to the wild ones.

Studies on self-recognition have classically used the mirror test to study this capacity in different species (Gallup, 1970) and have been done with different primate species. Results indicate that only a few species pass the test successfully, leading to the suggestion that only humans, chimpanzees, gorillas, and some orangutans have a notion of self (Byrne, 1995; Eddy, Gallup, \& Povinelli, 1996; Gallup et al., 1971; Hauser, 2000; but see recent positive result in elephants, Plotnik, de Waal, \& Reiss, 2006, and dolphins, Reiss \& Marino, 2001). However, the performances of the chimpanzees were mixed, as some succeeded, whereas others did not. A careful analysis of the evidence suggested that early experience of the individual explains these results, with individuals living in isolation failing the tests, whereas those having a richer social environment succeeding (de Veer \& Van de Bos, 1999; Gallup et al., 1971; Van de Bos, 1999). Thus, empirical evidence clearly shows an effect of ontogenetic experience on cognitive abilities in chimpanzees.

More abundant evidence points clearly toward a strong effect of living conditions on the cognitive performance of the chimpanzees. The single most important result of the last two decades of study of wild chimpanzees was the description of large intraspecific behavioral diversity, including all aspects of their behavior, ranging from social group size, group composition, and social interactions to sexual behavior, tool uses, hunting strategies, feeding techniques, and cultural traits (Boesch \& Boesch 1989, 1990; Boesch \& Boesch-Achermann, 2000; Boesch, Hohmann, \& Marchant, 2002; McGrew, Nishida, \& Marchant, 1996; Mitani, Watts, \& Muller, 2002; Whiten et al., 1999, 2001; Wrangham, McGrew, de Waal, \& Heltne, 1994). Given that large parts of the chimpanzee range are totally unknown to science, researchers must assume that this behavioral diversity will only increase as more new populations are studied. For example, new types of tool uses have been described in the Goualougo Triangle chimpanzees of northern Congo (Sanz, Morgan, \& Gulick, 2004); in Cameroon (Morgan \& Abwe, 2006), cave use along with spear use in hunting have been described for the first time in this species; in Senegal (Pruetz, 2001; Pruetz \& Bertolani, 2007), well-digging in Semliki chimpanzees from Uganda (Hunt \& McGrew, 2002) and feeding on underground tubers in Tongo chimpanzees from the Democratic Republic of Congo (Lanjouw, 2002) have been described.
In addition, there is a large and growing body of evidence showing that in other species the conditions of upbringing directly affect performance on psychological tests. The famous dog, Rico, that has been lovingly trained by her owner for years to learn hundreds of toys by name out-competed the performance of other dogs on some learning tasks and exhibited some learning abilities previously thought to be restricted to humans (Kaminski, Call, \& Fischer, 2004). Similar effects has been observed for parrots and captive chimpanzees that were reared in rich environments featuring constant contact with human caretakers and daily enrichment and stimulation in the form of artificial language training lessons (de Waal, 2001; Pepperberg, 1987; Savage-Rumbaugh et al., 1980).

In conclusion, all evidence suggests that experience is very important and seems to affect cognitive development in chimpanzees. This is clearly in agreement with the predictions of the developmentalist approach and conflicts with the deterministic approach. In other words, many of the conclusions reached by comparative psychology experiments are based on unreliable assumptions. I am suggesting that researchers need to take into account the upbringing conditions of the subjects they are testing if they are going to understand cognitive differences between species.

\section{Designing Ways to Compare Species: The Experiment Paradox}

Experimental studies exploring interspecific differences in behavior need to rely on carefully designed procedures for the comparison to be valid. Experiments should be favored when different, alterable factors may lead to the observed behavior. In theory, experiments work by manipulating the variables that are of interest while keeping constant those that are not (Campbell \& Stanley, 1963, 1966; Spector, 1981). To accomplish such an ideal, some have tried to present similar conditions to both human and chimpanzee subjects, for example, both were tested in the same cages (Wolfle \& Wolfle, 1939). In practice, however, the vast majority of experimental procedures used in comparative cognitive sciences violate this central experimental paradigm. In the comparative cognitive studies including human subjects, many key differences are systematically introduced into the experiment procedures:

1. Human subjects are selected from free-ranging individuals living in natural social groups, whereas ape subjects are selected from captive individuals living in deprived social groups;

2. Human subjects are tested with conspecifics, whereas ape subjects are tested with members of another species (normally humans);

3. Humans subjects are tested in the same room as the experimenters, whereas ape subjects are separated by physical barriers from the experimenters;

4. Infant human subjects are in close proximity to one of their parents during testing, whereas infant ape subjects are separated from their biological mothers during testing; 
Table 4

Presence of Biases Introduced in Experimental Procedures in Recently Published Comparative Work, Including Humans and Apes

\begin{tabular}{|c|c|c|c|c|c|c|c|}
\hline Species compared & $\begin{array}{l}\text { Bias } 1 \\
\text { captive }\end{array}$ & $\begin{array}{c}\text { Bias } 2 \\
\text { conspecific }\end{array}$ & $\begin{array}{l}\text { Bias } 3 \\
\text { barrier }\end{array}$ & $\begin{array}{l}\text { Bias } 4 \\
\text { parent }\end{array}$ & $\begin{array}{c}\text { Bias } 5 \\
\text { artificial }\end{array}$ & Outcome $^{\mathrm{a}}$ & Reference \\
\hline $\mathrm{H}-\mathrm{C}-\mathrm{G}-\mathrm{O}$ & $\mathrm{x}$ & $\mathrm{x}$ & $\mathrm{x}$ & & $\mathrm{x}$ & $\mathrm{H}=\mathrm{C}$ & Barth \& Call, 2006 \\
\hline $\mathrm{H}-\mathrm{C}$ & $\mathrm{x}$ & & & & & $\mathrm{H}=\mathrm{C}$ & Horner et al., 2006 \\
\hline $\mathrm{H}-\mathrm{C}-\mathrm{G}-\mathrm{O}$ & $\mathrm{x}$ & $\mathrm{x}$ & $\mathrm{x}$ & $\mathrm{x}$ & $\mathrm{x}$ & $\mathrm{H}>\mathrm{C}$ & Haun, Call, et al., 2006 \\
\hline $\mathrm{H}-\mathrm{C}$ & $\mathrm{x}$ & $\mathrm{x}$ & $\mathrm{x}$ & $\mathrm{x}$ & $\mathrm{x}$ & $\mathrm{H}>\mathrm{C}$ & Collier-Baker \& Suddendorf, 2006 \\
\hline $\mathrm{H}-\mathrm{C}-\mathrm{O}$ & $\mathrm{x}$ & $\mathrm{x}$ & $\mathrm{x}$ & $\mathrm{x}$ & $\mathrm{x}$ & $\mathrm{H}>\mathrm{C}$ & Poss \& Rochat, 2003 \\
\hline $\mathrm{H}-\mathrm{C}-\mathrm{O}$ & $\mathrm{x}$ & $\mathrm{x}$ & $\mathrm{x}$ & $\mathrm{x}$ & $\mathrm{x}$ & $\mathrm{H}>\mathrm{C}$ & Call, 2001 \\
\hline $\mathrm{H}-\mathrm{C}$ & $\mathrm{x}$ & & $\mathrm{x}$ & & $\mathrm{x}$ & $\mathrm{H} \neq \mathrm{C}$ & Fagot \& Tomonaga, 1999 \\
\hline $\mathrm{H}-\mathrm{C}-\mathrm{O}$ & $\mathrm{x}$ & $\mathrm{x}$ & & $\mathrm{x}$ & & $\mathrm{H}=\mathrm{C}$ & Itakura \& Tanaka, 1998 \\
\hline $\mathrm{H}-\mathrm{C}-\mathrm{O}$ & $\mathrm{x}$ & $\mathrm{x}$ & $\mathrm{x}$ & $\mathrm{x}$ ? & $\mathrm{x}$ & $\mathrm{H}>\mathrm{C}$ & Call \& Tomasello, 1998 \\
\hline $\mathrm{H}-\mathrm{O}$ & $\mathrm{x}$ & $\mathrm{x}$ & $\mathrm{x}$ & & & $\mathrm{H}=\mathrm{OO}$ & Call \& Tomasello, 1996 \\
\hline $\mathrm{H}-\mathrm{C}$ & $\mathrm{x}$ & $\mathrm{x}$ & $\mathrm{x} /-$ & $\mathrm{x} /-$ & & $\mathrm{H}>\mathrm{C}$ & Whiten, 1996 \\
\hline $\mathrm{H}-\mathrm{O}$ & $\mathrm{x}$ & $\mathrm{x} /-$ & $\mathrm{x} /-$ & & $\mathrm{x}$ & $\mathrm{H}>\mathrm{O}$ & Call \& Tomasello, 1995 \\
\hline $\mathrm{H}-\mathrm{C}$ & $\mathrm{x}$ & $\mathrm{x}$ & & $\mathrm{x}$ & $\mathrm{x}$ & $\mathrm{H}>\mathrm{C}$ & Warneken et al., 2006 \\
\hline $\mathrm{H}-\mathrm{C}-\mathrm{G}-\mathrm{O}$ & $\mathrm{x}$ & $\mathrm{x}$ & $\mathrm{x}$ & $\mathrm{x}$ & $\mathrm{x}$ & $\mathrm{H}>\mathrm{C}$ & Haun, Rapold, et al., 2006 \\
\hline $\mathrm{H}-\mathrm{C}$ & $\mathrm{x}$ & $\mathrm{x}$ & $\mathrm{x}$ & $\mathrm{x}$ & $\mathrm{x}$ & $\mathrm{H}>\mathrm{C}$ & Warneken \& Tomasello, 2006 \\
\hline $\mathrm{H}-\mathrm{C}-\mathrm{O}$ & $\mathrm{x}$ & $\mathrm{x}$ & $\mathrm{x}$ & & $\mathrm{x}$ & $\mathrm{H}>\mathrm{C}$ & Call \& Tomasello, 1999 \\
\hline $\mathrm{H}-\mathrm{C}$ & $\mathrm{x}$ & & & & $\mathrm{x}$ & $\mathrm{H} \neq \mathrm{C}$ & Call et al., 2005 \\
\hline $\mathrm{H}-\mathrm{C}$ & $\mathrm{x} /-$ & $\mathrm{x}$ & & & & $\mathrm{H}<\mathrm{C}$ & Horner \& Whiten, 2005 \\
\hline $\mathrm{H}-\mathrm{C}$ & $\mathrm{x}$ & & $\mathrm{x}$ & & $\mathrm{x}$ & $\mathrm{H} \neq \mathrm{C}$ & Fagot \& Tomonaga, 2001 \\
\hline $\mathrm{H}-\mathrm{C}$ & $\mathrm{x}$ & $\mathrm{x}$ & $\mathrm{x}$ & $\mathrm{x}$ ? & $\mathrm{x}$ & $\mathrm{H}>\mathrm{C}$ & Call, 2001 \\
\hline $\mathrm{H}-\mathrm{C}$ & $\mathrm{x}$ & $\mathrm{x}$ & & & $\mathrm{x}$ & $\mathrm{H} \neq \mathrm{C}$ & Tomonaga, 1998 \\
\hline $\mathrm{H}-\mathrm{C}-\mathrm{B}$ & $\mathrm{x}$ & $\mathrm{x}$ & $\mathrm{x}$ & $\mathrm{x}$ & $\mathrm{x}$ & $\mathrm{H}>\mathrm{C}$ & Herrmann \& Tomasello, 2006 \\
\hline $\mathrm{H}-\mathrm{C}$ & $\mathrm{x}$ & $\mathrm{x}$ & & & & $\mathrm{H}=\mathrm{C}$ & Murai, 2006 \\
\hline Total & 23 & 19 & 17 & 12 & 17 & & \\
\hline$\%$ & 100 & 82 & 74 & 52 & 74 & & \\
\hline
\end{tabular}

Note. For further explanation on the five experimental biases, refer to the text. $\mathrm{H}=$ human; $\mathrm{C}=$ chimpanzee; $\mathrm{G}=$ gorilla; $\mathrm{O}=$ orangutan; $\mathrm{B}=$ bonobo; $\mathrm{x}=$ bias being present; $\mathrm{x}$ ? = bias most likely present but not mentioned in the method; $\mathrm{x} /-=$ bias present for only some of the group tested.

${ }^{a}$ Outcomes are presented according to the judgments made by the authors of the studies; $\mathrm{H}=\mathrm{C}$ when both species performed equally; $\mathrm{H}>\mathrm{C}$ when humans were judged to perform qualitatively in a more elaborate way than chimpanzees; $\mathrm{H}<\mathrm{C}$ when chimpanzees were judged to perform qualitatively in a more elaborate way than humans; $\mathrm{H} \neq \mathrm{C}$ when both species performed differently, and the authors did not judge any one way as better.

5. Human subjects are tested about conspecific tasks with conspecific materials, whereas ape subjects are tested about human tasks with human materials.

The introduction of such systematic biases in the experimental procedures is very questionable, as it might directly affect the outcome of the experiments (see de Waal, 2001). In a review of the last 10 years in 12 top scientific journals and magazines, ${ }^{1}$ I found 23 publications directly comparing human with chimpanzee performance on cognitive tasks (see Table 4). All of them compared captive chimpanzees with free living humans that were in all cases young children living in their natural families and that came to the research institutions only for the experiments. The vast majority used human experimenters/demonstrators with the chimpanzees and physical barriers to isolate the chimpanzees from the human experimenters. Significantly more studies that used physical barriers for chimpanzees and not for humans concluded that humans were superior to chimpanzees than those studies avoiding the use of physical barriers (barrier: 13 of 16 studies; no barrier: 1 of 7 studies; Fisher exact test: $p=.0049)$. Similarly, significantly more studies that allowed the presence of one parent only for human children concluded that humans were superior to chimpanzees than studies that avoided the presence of parents during the testing (parent present: 11 of 12 studies; no parent: 3 of 11 studies; Fisher exact test: $p=.0028$ ). Finally, all comparative studies that used physical barriers and allowed the presence of one parent for children concluded that humans were superior $(n=10)$, whereas none of the studies avoiding both did so $(n=5$; Fisher exact test: $p=.0003$ ). It is interesting that in this data set the use of a human experimenter did not seem to have an influence on the conclusion that humans perform better than chimpanzees (Fisher exact test: $p=.126)$. Taken together, this review highlights the large impact some aspects of the testing procedures might have on the results in a species comparison test.

Striking examples of such biased procedures are seen when researchers compare-for the understanding of communicative signals-Westerner human subjects sharing the same room with the experimenters and one of their parents with subjects of one species isolated behind physical barriers from the experimenters (see pictures illustrating this in Bräuer, Kaminski, Riedel, Call, \& Tomasello, 2006; Herrmann \& Tomasello, 2006; Povinelli, 2000). This biased procedure alters some important features of the communicative signals presented: For example, a pointing gesture would be either directly aimed at one object (the same room condition) or indirectly through another object (the physical barrier condition) while at the same time affecting the distance separating

\footnotetext{
${ }^{1}$ The journals and magazines reviewed include the following: Journal of Comparative Psychology, Animal Cognition, Journal of Experimental Psychology, Animal Behaviour, Science, Nature, Developmental Psychology, Current Biology, Cognition, Developmental Science, Developmental Psychology, and Behavioural Processes.
} 
the objects, which is known to influence species-specific perception in chimpanzees and humans (Fagot \& Tomonaga, 2001).

Although I can fully understand why some of these biases are introduced, for example it might be very stressful to separate a baby from its mother, it remains that biased interspecific treatments introduce a systematic confounding variable into the experimental protocol. Because such bias could lead to important differences in the results between the two groups tested, it is puzzling that the effect of such differences has never been systematically studied. The introduction of Bias 4 (parent present) is even more problematic, as it allows for extensive uncontrolled "Clever Hans" effects-named after the horse whose apparent mathematical knowledge was derived from its ability to read unconscious clues provided by its owner/experimenter. By allowing for physical contact in experiments (children are often sitting on the lap of one of their parents, or they have direct visual contact with a parent), experimental procedures allow for many uncontrolled clues to be exchanged (see the following video sequence from Warneken \& Tomasello, 2006, which perfectly exemplifies how uncontrolled Clever Hans effects influence human children when tested with one of their parents present: www.sciencemag.org/content/vol311/ issue5765/images/data/1301/DC1/11211448s3.mpg). Only recently have some researchers started to address the effects of different methods used within one species on the performance of the subjects and have concurred in concluding that it yields different results (Barth, Reaux, \& Povinelli, 2005; Miklósi \& Soproni, 2006; Sousa, Okamoto, \& Matsuzawa, 2003). Adding control trials to evaluate the effects of the different bias introduced in such experiments would easily allow quantifying them, but as far as I know this has never been done.

In addition, such systematic differences are perceived as bias even by those who use them, as they will be avoided whenever judged possible. For example, in cognitive experiments comparing dogs with other species, the captive and physical barrier biases were not imposed on the dogs (see pictures of experiment procedures in, e.g., Bräuer et al., 2006; Hare \& Tomasello, 2004; Miklósi, Pongracz, Lakatos, Topal, \& Csanyi, 2005), even when apes and dogs were directly compared (Bräuer et al., 2006). In the discussion about dogs, chimpanzees, and human cognitive abilities, the fact that only the chimpanzees were forced to experience the captive and physical barrier biases has never been considered.

The other major problem with such systematic biases is that experiments that were designed to answer one question might actually address a very different one. Bias 2 (human experimenter) confuses the issues of within- versus between-species cognitive knowledge. For example, Bias 2 does not allow investigation of the presence of a theory of mind in chimpanzees but only the ability of chimpanzees to attribute a theory of mind to humans (see also de Waal, 2001). These two questions have been systematically confused (Povinelli, 1994, 1996; Povinelli \& Vonk, 2003; Premack \& Woodruff, 1978; Tomasello, 1999; Tomasello et al., 2005), and only in a very few number of studies in which chimpanzees have been tested with other chimpanzees has the first question been addressed (Hare, Call, Agnetta, \& Tomasello, 2000; Hare, Call, \& Tomasello, 2001). As is the case in humans (Barrett, Richert, \& Driesenga, 2001), chimpanzees do better when tested on their understanding of conspecifics than on their understanding of members of other species.
The use of experiments in comparative psychology faces a paradox. They are favored because such experiments are an effective and sometimes the only way to systematically control for the effects of a single factor, but at the same time, they are systematically biased by the introduction of asymmetrical treatment conditions potentially disfavoring one of the two species compared. My recommendation would be to compare what is comparable. To that end, researchers should discern and avoid bias in experimental designs or to the least evaluate the effect of such biases if they cannot be avoided.

At the same time, one gets the impression that researchers must choose between doing controlled experiments in captive settings or collecting uncontrolled anecdotes from observing wild animals (Bernstein, 1988; Tomasello \& Call, 1997). However, such a dichotomy is a pure artifact of different schools of thought. Behavioral ecologists - since the pioneering works of the field's founders, Niko Tinbergen and Konrad Lorenz-have been conducting experiments in the field with wild animals (Alcock, 1989; Krebs \& Davies, 1997; Lorenz, 1981; Ridley, 1996; Tinbergen, 1951). For example, many aspects of reproductive strategies, partner choice, and feeding tactics have been elucidated thanks to cleverly designed experiments done in the field that included controls for alternative explanations. Therefore, I think it is time to move away from such an artificial dichotomy and to take on the challenge of doing experiments in the field in primate studies, as has been done successfully by a few pioneers (Cheney \& Seyfarth, 1990).

\section{Discussion}

To understand how humans are different from other species, researchers need comparison of cognitive abilities among humans and other species - particularly between humans and their close relatives the African great apes. However, the comparative approaches taken in most psychological studies are of questionable value for two major reasons: First, differences within species have not been taken into account, and second, experimental procedures have differed systematically between species. Thus, what has been presented as "comparisons between humans and chimpanzees" has really represented "comparisons between WMC humans and captive chimpanzees." Any comparison between humans and chimpanzees requires an assessment of the breadth of variation in the emergence and presence of cognitive abilities within each species. Different environmental conditions or upbringing experiences affect the emergence and development of different cognitive abilities. Each one population in a given species may thus represent only one point within the spectrum of the cognitive variability present within that species. The social deprived environment and limited physical demands of some captive conditions are predicted to select for limited cognitive skills in those domains, as will the nature sterile lifestyle of Westerner city dwellers in the domain of folk biology.

This review shows that individuals need a phase during their up-bringing during which they face conditions that challenge them for any experienced-based ability to develop. Such an "ecological imprint" would select for the development of ability to solve such challenges. If, however, the situations are never or infrequently encountered, experienced-based cognitive abilities will remain absent or develop only partially. Some cultural psychologists have 
proposed an eco-cultural model to explain differences in the cognitive development observed between some human cultures (Segall et al., 1999), and some social psychologists have proposed a similar idea to explain the development of some social cognitive traits (Carpendale \& Lewis, 2004). I propose, however, to generalize this idea to all large brain animal species capable of learning for which social and ecological experiences in early life are going to be determinant for constructing their cognitive abilities. Such ecological imprints have been documented in humans, for example, (a) when the acquisition of theory of mind abilities is facilitated when more specific social stimulations are encountered early in life (Carpendale \& Lewis, 2004; Cutting \& Dunn, 2006; Peterson \& Slaughter, 2003; Ruffman et al., 1998; Ruffman, Slade, \& Crowe, 2002), (b) when coins and cash economy practice facilitates the acquisition of abstract and representational arithmetic (Saxe \& Esmonde, 2004, 2005), or (c) when the traditional farming way of life selects for a topographic notion of space, whereas a hunter-gatherer one favors a Euclidean notion of space (Dasen, 1982). Ecological imprinting predicts that individuals growing in isolation or impoverished social environments will acquire less social skills than those living in large families within large social groups. Similarly, it expects that animals living in a cage will acquire less spatial knowledge than those ranging freely within a $15 \mathrm{~km}^{2}$ home range of tropical rainforest. Therefore, cross-species comparisons should be restricted to individuals that have faced a similar ecological imprint.

Comparing individuals that have faced different ecological imprints will almost per definition lead to significant differences that, however, do not reflect species differences. The famous example of Kanzi, the baby bonobo, growing near his mother that was daily trained without success to use symbolic signs for years (whereas Kanzi spontaneously developed sophisticated skills that still set him apart from other apes), illustrates well how special imprinting situations dramatically stimulate the development of cognitive capacities (Savage-Rumbaugh, et al., 1980). Similar results were seen with $\mathrm{Ai}$, the female chimpanzee that has been solving arithmetic problems for the last 25 years, whose infant watched her solve many tasks and later developed spontaneously exceptionally early and proficient skills at match-to-sample tasks (Sousa et al., 2003). Some have spoken of enculturated apes developing humanspecific abilities (Call \& Tomasello, 1996; Tomasello, 1999) without appreciating that upbringing experience is a natural process faced by all individuals that has a key influence on experiencedbased cognitive development (see also de Waal, 2001).

Comparing cognitive abilities of different species under an evolutionary approach will allow realizing (a) that cognitive abilities might not be totally similar in all members of one species, (b) that cognitive abilities are affected by the living conditions, and (c) that researchers need to think in terms of variance in cognitive abilities. Favoring comparisons between individuals of different species that faced similar ecological imprinting experiences under similar sets of natural selection pressures will permit more meaningful comparisons. The variance of cognitive abilities is expected to be larger in humans, as they live in more diverse environmental conditions than any other primates, and this might well be a specificity of the human species. Until this is done, many of the conclusions of species differences in cognitive domains are artifacts based on unequal comparisons and do not reflect true species differences. Greater care in comparing species is required if re- searchers ever want to answer the question of "what makes us human."

\section{References}

Alcock, J. (1989). Animal behavior: An evolutionary approach (4th ed.). Sunderland, England: Sinauer Associates.

Altmann, J. (1980). Baboon mothers and infants. Cambridge, MA: Harvard University Press.

Astington, J., \& Baird, J. (2004). Why language matters for theory of mind. International Society for the Study of Behavioural Development Newsletter, 45(1), 7-9.

Atkinson, D., \& Thorndyke, M. (2001). The nature of animal developmental ecology: Integrating the "how" and the "why." In D. Atkinson \& M. Thorndyke (Eds.), Environment and animal development: Genes, life histories and plasticity (pp. 1-28). Oxford, England: Bios Scientific Publishers.

Atran, S., Medin, D., \& Ross, N. (2005). The cultural mind: Environmental decision making and cultural modeling within and across populations. Psychological Review, 112, 744-775.

Avis, J., \& Harris, P. (1991). Belief-desire reasoning among Baka children: Evidence for a universal conception of mind. Child Development, 62, $460-467$.

Barnard, A. (2000). History and theory in anthropology. Cambridge, England: Cambridge University Press.

Barrett, J., Richert, R., \& Driesenga, A. (2001). God's beliefs versus mother's: The development of nonhuman agent concepts. Child Development, 72, 50-65.

Barth, J., \& Call, J. (2006). Tracking the displacement of objects: A series of tasks with great apes (Pan troglodytes, Pan paniscus, Gorilla gorilla and Pongo pygmaeus) and young children (Homo sapiens). Journal of Experimental Psychology, 32, 239-252.

Barth, J., Reaux, J., \& Povinelli, D. (2005). Chimpanzees' (Pan troglodytes) use of gaze cues in object-choice tasks: Different methods yield different results. Animal Cognition, 8, 84-92.

Bernstein, I. (1988). Metaphor, cognitive belief and science. Behavioral and Brain Sciences, 11, 247.

Berry, J., Poortinga, Y., Segall, M., \& Dasen, P. (2002). Cross-cultural Psychology: Research and applications (2nd ed.). Cambridge, England: Cambridge University Press.

Boesch, C. (1993). Toward a new image of culture in chimpanzees. Behavioral and Brain Sciences, 16, 514-515.

Boesch, C., \& Boesch, H. (1989). Hunting behavior of wild chimpanzees in the Taï National Park. American Journal of Physical Anthropology, 78, 547-573.

Boesch, C., \& Boesch, H. (1990). Tool use and tool making in wild chimpanzees. Folia Primatologica, 54, 86-99.

Boesch, C., \& Boesch-Achermann, H. (2000). The chimpanzees of the Taï forest: Behavioural ecology and evolution. Oxford, England: Oxford University Press.

Boesch, C., Hohmann, G., \& Marchant, L. (2002). Behavioural diversity in chimpanzees and bonobos. Cambridge, England: Cambridge University Press.

Bowler, P. (1989). Evolution: The history of an idea (Rev. ed.). Los Angeles: University of California Press.

Bräuer, J., Kaminski, J., Riedel, J., Call, J., \& Tomasello, M. (2006). Making inferences about the location of hidden food: Social dog, causal ape. Journal of Comparative Psychology, 120, 38-47.

Brown, P., \& Levinson, S. (2000). Frames of spatial reference and their acquisition in Tenejapan Tzeltan. In L. Nucci, G. Saxe, \& E. Turiel (Eds.), Culture, thought and development (pp. 167-197). New York: Erlbaum.

Byrne, R. (1995). The thinking ape. Oxford, England: Oxford University Press. 
Call, J. (2001). Object permanence in orangutans (Pongo pygmaeus), chimpanzees (Pan troglodytes), and children (Homo sapiens). Journal of Comparative Psychology, 115, 159-171.

Call, J., Carpenter, M., \& Tomasello, M. (2005). Copying results and copying actions in the process of social learning: Chimpanzees (Pan troglodytes) and human children (Homo sapiens). Animal Cognition, 8, 151-163.

Call, J., \& Tomasello, M. (1995). Use of social information in the problem solving of orangutans (Pongo pygmaeus) and human children (Homo sapiens). Journal of Comparative Psychology, 109, 308-320.

Call, J., \& Tomasello, M. (1996). The effect of humans on the cognitive development of apes. In A. Russon, K. Bard, \& S. Parker (Eds.), Reaching into thought: The minds of the great apes (pp. 371-403). Cambridge, England: Cambridge University Press.

Call, J., \& Tomasello, M. (1998). Distinguishing intentional from accidental actions in orangutans (Pongo pygmaeus), chimpanzees (Pan troglodytes), and human children (Homo sapiens). Journal of Comparative Psychology, 112, 192-206.

Call, J., \& Tomasello, M. (1999). A nonverbal false belief task: The performance of children and great apes. Child Development, 70, 381395

Callaghan, T., Rochat, P., Lillard, A., Claux, M., Odden, H., Itakura, S., et al. (2005). Synchrony in the onset of mental-state reasoning. Psychological Science, 16, 378-384.

Campbell, D. T., \& Stanley, J. C. (1963). Experimental and quasiexperimental designs for research on teaching. In N. L. Gage (Ed.), Handbook of research on teaching (pp. 65-84). Chicago: Rand McNally.

Campbell, D. T., \& Stanley, J. C. (1966). Experimental and quasiexperimental designs for research. Skokie, IL: Rand McNally.

Cantlon, J., \& Brannon, E. (2007). Adding up the effects of cultural experience on the brain. Trends in Cognitive Sciences, 11, 1-4.

Carpendale, J., \& Lewis, C. (2004). Constructing an understanding of mind: The development of children's social understanding within social interaction. Behavioral and Brain Sciences, 27, 79-151.

Carruthers, P., \& Smith, P. (1996). Theories of theories of mind. Cambridge, England: Cambridge University Press.

Cheney, D., \& Seyfarth, R. (1990). How monkeys see the world: Inside the mind of another species. Chicago: Chicago University Press.

Choi, I., Nisbett, R., \& Norenzayan, A. (1999). Causal attribution across cultures: Variation and universality. Psychological Bulletin, 125, 47-63.

Clutton-Brock, T., Albon, S. D., \& Guiness, F. E. (1984, March 22). Maternal dominance, breeding success, and birth sex ratios in red deer. Nature, 308, 358-360.

Cole, M. (2006). Culture and cognitive development in phylogenetic, historical, and ontogenetic perspective. In E. Kuhn \& R. Siegler (Eds.), Handbook of child psychology: Culture and cognitive development in phylogenetic, historical, and ontogenetic perspective (pp. 636-683). Hoboken, NJ: Wiley.

Collier-Baker, E., \& Suddendorf, T. (2006). Do chimpanzees (Pan troglodytes) and 2-year-old children (Homo sapiens) understand double invisible displacement? Journal of Comparative Psychology, 120, 8997.

Correa-Chavez, M., \& Rogoff, B. (2005). Cultural research has transformed our ideas of cognitive development. International Society for the Study of Behavioral Development Newsletter, 47, 7-10.

Cutting, A., \& Dunn, J. (1999). Theory of mind, emotion understanding, language, and family background: Individual differences and interrelations. Child Development, 70, 853-865.

Cutting, A., \& Dunn, J. (2006). Conversations with siblings and with friends: Links between relationship quality and social understanding. British Journal of Developmental Psychology, 24, 73-87.

Darwin, C. (1859). The origin of species. London: Murray.

Dasen, P. R. (1982). Cross-cultural data on operational development:
Asymptotic development curves. In T. Bever (Ed.), Regressions in mental development: Basic phenomena and theories (pp. 221-232). Hillsdale, NJ: Erlbaum.

Dasen, P. R., Inhelder, B., Lavallée, M., \& Reitschitzki, J. (1978). La naissance de l'intelligence chez l'enfant Baoulé de Côte d'Ivoire [The birth of intelligence in the Baoulé child in Côte d'Ivoire]. Berne, Switzerland: Hans Huber.

Dasen, P., \& Mishra, R. (2000). Cross-cultural views on human development in the third millennium. International Journal of Behavioral Development, $24,428-434$.

Davenport, R. K. (1979). Some behavioral disturbances of great apes in captivity. In D. A. Hamburg \& E. McCown (Eds.), The great apes (pp. 341-357). Menlo Park, CA: Benjamin/Cummings.

Dawkins, R. (1986). The blind watchmaker. London: Longmans.

De León, L. (1994). Exploration in the acquisition of geocentric location by Tzotzil children. Linguistics, 32, 857-884.

de Veer, M., \& Van de Bos, R. (1999). A critical review of methodology and interpretation of mirror self recognition research in nonhuman primates. Animal Behaviour, 58, 459-468.

de Waal, F. (1982). Chimpanzee politics: Power and sex among apes. London: Jonathan Cape.

de Waal, F. (2001). The ape and the sushi master: Cultural reflections of a primatologist. New York: Basic Books.

Eddy, T., Gallup, G., \& Povinelli, D. (1996). Age differences in the ability of chimpanzees to distinguish mirror-images of self from video images of others. Journal of Comparative Psychology, 110, 38-44.

Evans, J. (2003). In two minds: Dual-process accounts of reasoning. Trends in Cognitive Sciences, 7, 454-459.

Fagot, J., \& Tomonaga, M. (1999). Comparative assessment of global-local processing in humans (Homo sapiens) and chimpanzees (Pan troglodytes): Use of a visual search task with compound stimuli. Journal of Comparative Psychology, 113, 3-12.

Fagot, J., \& Tomonaga, M. (2001). Effects of element separation on perceptual grouping by humans (Homo sapiens) and chimpanzees (Pan troglodytes): Perception of Kanizsa illusory figures. Animal Cognition, 4, 171-177

Galef, B. (1988). Imitation in animals. In B. Galef \& T. Zentrall (Eds.), Social learning: Psychological and biological perspectives (pp. 3-28). Hillsdale, NJ: Erlbaum.

Galef, B. (1990). Tradition in animals: Field observations and laboratory analyses. In M. Bekoff \& D. Jamieson (Eds.), Interpretation and explanation in the study of animal behavior (pp. 74-95). Boulder, CO: Westview Press.

Gallup, G. (1970, January 2). Chimpanzee: Self-recognition. Science, 167 $86-87$.

Gallup, G., McClure, M., Hill, S., \& Bundy, R. (1971). Capacity for self-recognition in differentially reared chimpanzees. Psychological Record, 21, 69-74.

Gardner, B. T., \& Gardner, R. A. (1989). Prelinguistic development of children and chimpanzees. Human Evolution, 4, 433-460.

Gardner, R. (2005). Animal cognition meets evo-devo. Behavioral and Brain Sciences, 28, 699-700.

Geary, D. (2005). The origin of mind: Evolution of brain, cognition, and general intelligence. Washington, DC: American Psychological Association.

Gopnik, A., \& Meltzoff, A. (1994). Minds, bodies and persons: Young children's understanding of the self and others as reflected in imitation and theory of mind research. In S. Parker, R. Mitchell, \& M. Boccia (Eds.), Self-awareness in animals and humans (pp. 166-186). Cambridge, England: Cambridge University Press.

Gordon, P. (2004, October 15). Numerical cognition without words: Evidence from Amazonia. Science, 306, 496-499.

Hala, S., \& Chandler, M. (1996). The role of strategic planning in accessing false-belief understanding. Child Development, 67, 2948-2966. 
Hare, B., Call, J., Agnetta, B., \& Tomasello, M. (2000). Chimpanzees know what conspecifics do and do not see. Animal Behaviour, 59, 771-785.

Hare, B., Call. J., \& Tomasello, M. (2001). Do chimpanzees know what conspecifics know? Animal Behaviour, 61, 139-151.

Hare, B., \& Tomasello, M. (2004). Chimpanzees are more skillful in competitive than in cooperative cognitive tasks. Animal Behaviour, 68, 571-581.

Harlow, H., \& Harlow, M. (1962). Social deprivation in monkeys. Scientific American, 207, 136-146.

Harlow, H., \& Harlow, M. (1965). The affectional system. In A. Schreier, H. Harlow, \& F. Stollnitz (Eds.), Behavior of nonhuman primates: Modern research trends (Vol. 2, pp. 287-334). New York: Academic Press.

Harlow, H., Harlow, M., \& Suomi, J. (1971). From thought to theory: Lessons from a primate laboratory. American Scientist, 59, 538-549.

Haun, D., Call, J., Janzen, G., \& Levinson, S. (2006). Evolutionary psychology of spatial representations in the Hominidae. Current Biology, 16, 1736-1740.

Haun, D., Rapold, C., Call, J., Janzen, G., \& Levinson, S. (2006). Cognitive cladistics and cultural override in Hominid spatial cognition. Proceedings of the National Academy of Sciences, USA, 103, 17568-17573.

Hauser, M. D. (2000). Wild minds: What animals really think. New York: Henry Holt and Company.

Herrmann, E., \& Tomasello, M. (2006). Apes' and children's understanding of cooperative and competitive motives in a communicative situation. Developmental Science, 9, 518-529.

Heyes, C. M. (1993). Anecdotes, training, trapping and triangulating: Do animals attribute mental states? Animal Behaviour, 46, 177-188.

Heyes, C. M. (1994). Imitation, culture and cognition. Animal Behaviour, 46, 999-1010.

Heyes, C. M. (1998). Theory of mind in nonhuman primates. Behavioral and Brain Sciences, 21, 101-134.

Hinde, R. (1971). Development of behavior. In A. Schreier, H. Harlow, \& F. Stollnitz (Eds.), Behavior of non-human primates: Modern research trends (Vol. 3, pp. 1-68). New York: Academic Press.

Holmes, H., Black, C., \& Miller, S. (1996). A cross-task comparison of false belief understanding in a Head Start population. Journal of Experimental Child Psychology, 63, 263-285.

Horner, V., \& Whiten, A. (2005). Causal knowledge and imitation/ emulation switching in chimpanzees (Pan troglodytes) and children (Homo sapiens). Animal Cognition, 8, 164-181.

Horner, V., Whiten, A., Flynn, E., \& de Waal, F. (2006). Faithful replication of foraging techniques along cultural transmission chains by chimpanzees and children. Proceedings of the National Academy of Sciences, USA, 103, 13878-13883.

Howe, N., Petrakos, H., \& Rinaldi, C. (1998). "All the sheep are dead. He murdered them": Sibling pretense, negotiation, internal state language, and relationship quality. Child Development, 69, 182-191.

Howe, N., Rinaldi, C., Jennings, M., \& Petrakos, H. (2002). "No! The lambs can stay out because they got cozies": Constructive and destructive sibling conflict, pretend play, and social understanding. Child Development, 73, 1460-1473.

Hunt, K., \& McGrew, W. (2002). Chimpanzees in the dry habitats of Assirik, Senegal, and Semliki Wildlife Reserve, Uganda. In C. Boesch, G. Hohmann, \& L. Marchant (Eds.), Behavioural diversity in chimpanzees and bonobos (pp. 35-51). Cambridge, England: Cambridge University Press.

Imura, T., Tomonaga, M., \& Yagi, A. (2006). Processing of shadow information in chimpanzee (Pan troglodytes) and human (Homo sapiens) infants. In T. Matsuzawa, M. Tomonaga, \& M. Tanaka (Eds.), Cognitive development in chimpanzees (pp. 305-316). Tokyo, Japan: Springer Verlag.

Itakura, S., \& Tanaka, M. (1998). Use of experimenter-given cues during object-choice tasks by chimpanzees (Pan troglodytes), an orangutan (Pongo pygmaeus), and human infants (Homo sapiens). Journal of Comparative Psychology, 112, 119-126.

Jolly, A. (1999). Lucy's legacy: Sex and intelligence in human evolution. Cambridge, MA: Harvard University Press.

Kaminski, J., Call, J., \& Fischer, J. (2004, June 11). Word learning in a domestic dog: Evidence for "fast mapping." Science, 304, 1682-1683.

Knight, N., Sousa, P., Barrett, J., \& Atran, S. (2004). Children's attribution of belief to humans and God: Cross-cultural evidence. Cognitive Science, 28, 117-126.

Krebs, J. R., \& Davies, N. B. (1993). An introduction to behavioural ecology (3rd ed.). Oxford, England: Blackwell.

Krebs, J. R., \& Davies, N. B. (1997). Behavioural ecology (4th ed.). Oxford, England: Blackwell.

Kuper, A. (1999). Culture: An anthropologist perspective. Boston: Harvard University Press.

Laland, K., \& Janik, V. (2006). The animal cultures debate. Trends in Ecology and Evolution, 21, 542-547.

Lanjouw, A. (2002). Behavioural adaptations to water scarcity in Tongo chimpanzees. In C. Boesch, G. Hohmann, \& L. Marchant (Eds.), Behavioural diversity in chimpanzees and bonobos (pp. 52-60). Cambridge, England: Cambridge University Press.

Lefebvre, L., Nicolakakis, N., \& Boire, D. (2002). Tools and brains in birds. Behaviour, 139, 939-973.

Lefebvre, L., Whittle, P., Lascaris, E., \& Finkelstein, A. (1997). Feeding innovations and forebrain size in birds. Animal Behaviour, 53, 549-560.

Leslie, A., Friedman, O., \& German, T. (2004). Core mechanisms in "theory of mind." Trends in Cognitive Science, 8, 528-533.

Levinson, S., Kita, S., Haun, D., \& Rasch, B. (2002). Returning the tables: Language affects spatial reasoning. Cognition, 84, 155-188.

Lorenz, K. (1981). The foundation of ethology. New York: Simon \& Schuster.

Majid, A., Bowerman, M., Kita, S., Haun, D., \& Levinson, S. (2004). Can language restructure cognition? The case for space. Trends in Cognitive Science, 8, 108-114.

Mason, W. (1965). Determinants of social behavior in young chimpanzees In A. Schreier, H. Harlow, \& F. Stollnitz (Eds.), Behavior of nonhuman primates: Modern research trends (pp. 335-364). New York: Academic Press.

Mason, W. (1978). Social experience and primate cognitive development. In G. Burghardt \& M. Bekoff (Eds.), The development of behavior: Comparative and evolutionary aspects (pp. 233-251). New York: Garlan Press.

Matsuzawa, T. (2006). Sociocognitive development in chimpanzees: A synthesis of laboratory work and fieldwork. In T. Matsuzawa, M. Tomonaga, \& M. Tanaka (Eds.), Cognitive development in chimpanzees (pp. 3-33). Tokyo, Japan: Springer Verlag.

Maynard Smith, J. (1982). Evolution and the theory of games. Cambridge, England: Cambridge University Press.

McGrew, W. (1992). Chimpanzee material culture: Implications for human evolution. Cambridge, England: Cambridge University Press.

McGrew, W., Nishida, T., \& Marchant, L. (1996). Great apes societies. Cambridge, England: Cambridge University Press.

Medin, D., \& Atran, S. (2004). The native mind: Biological categorization and reasoning in development and across cultures. Psychological Review, 111, 960-983.

Meltzoff, A. (1995). Understanding the intentions of others: Re-enactment of intended acts by 18-month-old children. Developmental Psychology, $31,838-850$.

Meltzoff, A. (1996). The human infant as imitative generalist: A 20-year progress report on infant imitation with implications for comparative psychology. In B. Galef \& C. Heyes (Eds.), Social learning in animals: The roots of culture (pp. 347-370). New York: Academic Press.

Menzel, E., Davenport, R., \& Rogers, C. (1961). Effects of environmental 
restriction upon the chimpanzee's responsiveness in novel situation. Journal of Comparative Psychology, 56, 329-334.

Menzel, E., Davenport, R., \& Rogers, C. (1970). The development of tool-using in wild-born and restriction-reared chimpanzees. Folia Primatologica, 12, 273-283.

Miklósi, A., Pongracz, P., Lakatos, G., Topal, J., \& Csanyi, V. (2005). A comparative study of the use of visual communicative signals in interactions between dogs (Canis familiaris) and humans and cats (Felis catus) and humans. Journal of Comparative Psychology, 119, 179-186.

Miklósi, A., \& Soproni, K. (2006). A comparative analysis of animals' understanding of the human pointing gesture. Animal Cognition, 9, 81-93.

Mishra, R., Dasen, P., \& Niraula, S. (2003). Ecology, language and performance on spatial cognitive tasks. International Journal of Psychology, 38, 366-383.

Mitani, J., Watts, D., \& Muller, M. (2002). Recent development in the study of wild chimpanzee behaviour. Evolutionary Anthropology, 11, $9-25$.

Morgan, B., \& Abwe, E. (2006). Chimpanzees use stone hammers in Cameroon. Current Biology, 16, R632-R633.

Murai, C. (2006). Early spontaneous categorization in primate infantschimpanzees, humans, and Japanese macaques-with the familiarization-novelty preference task. In T. Matsuzawa, M. Tomonaga, \& M. Tanaka (Eds.), Cognitive development in chimpanzees (pp. 279304). Tokyo, Japan: Springer Verlag.

Murray, T. (1999). Human development theories: Windows on culture. Thousand Oaks, CA: Sage.

Nisbett, R., Peng, K., Choi, I., \& Norenzayan, A. (2001). Culture and systems of thought: Holistic versus analytic cognition. Psychological Review, 108, 291-310.

Norenzayan, A., \& Nisbett, R. (2000). Culture and causal cognition. Current Directions in Psychological Science, 9, 132-135.

Norenzayan, A., Smith, E., Kim, B., \& Nisbett, R. (2002). Cultural preferences for formal versus intuitive reasoning. Cognitive Science, 26, 653-684.

Pears, K., \& Moses, L. (2003). Demographics, parenting, and theory of mind in preschool children. Social Development, 12, 1-20.

Pepperberg, I. (1987). Evidence for conceptual quantitative abilities in the African Grey parrot: Labeling of cardinal sets. Ethology, 75, 37-61.

Perner, J., Ruffman, T., \& Leekam, S. (1994). Theory of mind is contagious: You catch it from your sibs. Child Development, 65, 1228-1238.

Peterson, C., \& Slaughter, V. (2003). Opening windows into the mind: Mothers' preferences for mental state explanations and children's theory of mind. Cognitive Development, 18, 399-429.

Piaget, J. (1935). La Naissance de l'Intelligence chez l'Enfant [The birth of intelligence in the child]. Neuchâtel, Switzerland: Delachaux et Niestlé.

Piaget, J. (1945). La Formation du Symbole chez l'Enfant [The formation of the symbol in the child]. Neuchâtel, Switzerland: Delachaux et Niestlé.

Piaget, J., \& Inhelder, B. (1947). La Représentation de l'Espace chez l'Enfant [The representation of space in the child]. Paris: Presses Universitaires de France.

Pica, P., Lemer, C., Izard, V., \& Dehaene, S. (2004, October 15). Exact and approximate arithmetic in an Amazonian indigene group. Science, 306, 499-503.

Plotnik, J., de Waal, F., \& Reiss, D. (2006). Self-recognition in an Asian elephant. Proceedings of the National Academy of Sciences, USA, 103, 17053-17057.

Poss, S., \& Rochat, P. (2003). Referential understanding of videos in chimpanzees (Pan troglodytes), orangutans (Pongo pygmaeus), and children (Homo sapiens). Journal of Comparative Psychology, 117, 420428 .

Povinelli, D. (1994). What chimpanzees (might) know about the mind. In R. Wrangham, W. McGrew, F. de Waal, and P. Heltne (Eds.), Chim- panzees cultures (pp. 285-300). Cambridge, MA: Harvard University Press.

Povinelli, D. (1996). Chimpanzee theory of mind? The long road to strong inference. In P. Carruthers \& P. Smith (Eds.), Theories of theories of mind (pp. 293-329). Cambridge, England: Cambridge University Press.

Povinelli, D. (1999). Social understanding in chimpanzees: New evidence from a longitudinal approach. In P. D. Zelazo, J. W. Astington, \& D. R. Olson (Eds.), Developing theories of intention: Social understanding and self-control (pp. 195-225). Mahwah, NJ: Erlbaum.

Povinelli, D. (2000). Folk physics for apes: The chimpanzee's theory of how the world works. Oxford, England: Oxford University Press.

Povinelli, D., \& Vonk, J. (2003). Chimpanzee minds: Suspiciously human? Trends in Cognitive Sciences, 7, 157-160.

Premack, D., \& Premack, A. J. (1983). The mind of an ape. New York: Norton.

Premack, D., \& Woodruff, G. (1978). Does the chimpanzee have a theory of mind? Behavioral and Brain Sciences, 4, 515-526.

Pruetz, J. (2001). Uses of caves by savanna chimpanzees (Pan troglodytes verus) in the Tomboronkoto region of southeastern Senegal. Pan Africa News, 8, 26-28.

Pruetz, J., \& Bertolani, P. (2007). Savanna chimpanzees (Pan troglodytes verus) hunt with tools. Current Biology, 17, 412-417.

Reader, S., \& Laland, K. (2002). Social intelligence, innovation, and enhanced brain size in primates. Proceedings of the National Academy of Sciences, USA, 99, 4436-4441.

Reiss, D., \& Marino, L. (2001). Mirror self-recognition in the bottlenose dolphin: A case of cognitive convergence. Proceedings of the National Academy of Sciences, USA, 98, 5937-5942.

Ridley, M. (1996). Evolution (2nd ed.). Oxford, England: Blackwell.

Rogers, C., \& Davenport, R. (1969). Effects of restricted rearing on sexual behaviour in chimpanzees. Developmental Psychology, 1, 200-204.

Rogoff, B. (1990). Apprenticeship in thinking: Cognitive development in social context. Oxford, England: Oxford University Press.

Ross, N., Medin, D., Coley, J., \& Atran, S. (2002). Cultural and experiential differences in the development of folk-biological induction. Cognitive Development, 107, 1-23.

Ruffman, T., Perner, J., Naito, M., Parkin, L., \& Clements, W. (1998), Older (but not younger) siblings facilitate false belief understanding. Developmental Psychology, 34, 161-174.

Ruffman, T., Slade, I., \& Crowe, E. (2002). The relation between children's and mothers' mental state language and theory of mind understanding. Child Development, 73, 734-751.

Rutherford, M. (2004). The effect of social role on theory of mind reasoning. British Journal of Psychology, 95, 91-103.

Sanz, C., Morgan, D., \& Gulick, S. (2004). New insights into chimpanzees, tools, and termites from the Congo basin. American Naturalist, 164, $567-581$.

Savage-Rumbaugh, E. S., Rumbaugh, D. M., \& Boysen, S. (1978). Linguistically mediated tool use and exchange by chimpanzees (Pan troglodytes). Behavioral and Brain Sciences, 201, 641-644.

Savage-Rumbaugh, E. S., Rumbaugh, D. M., \& Boysen, S. (1980). Do apes use language? American Scientist, 68, 49-62.

Saxe, G. (1981). Body parts as numerals: A developmental analysis of numeration among the Oksapmin in Papua New Guinea. Child Development, 52, 306-316.

Saxe, G. (1982). Developing forms of arithmetical thought among the Oksapmin of Papua New Guinea. Developmental Psychology, 18, 583594.

Saxe, G. B., \& Esmonde, I. (2004). Making change in Oksapmin trade stores: A study of shifting practices of quantification under conditions of rapid shift towards a cash economy. South Pacific Journal of Psychology, 15, 11-28

Saxe, G. B., \& Esmonde, I. (2005). Studying cognition in flux: A historical 
treatment of $F u$ in the shifting structure of Oksapmin mathematics. Mind, Culture and Activity, 12, 171-225.

Saxe, G., \& Moylan, T. (1982). The development of measurement operations among the Oksapmin of Papua New Guinea. Child Development, $53,1242-1248$.

Segall, M., Dasen, P., Berry, J., \& Poortinga, Y. (1999). Human behavior in global perspective: An introduction to cross-cultural psychology (2nd ed.). New York: Pergamon Press.

Sigg, H. (1980). Differentiation of female positions in hamadryas onemale-units. Zeitschrift für Tierpsychologie, 53, 265-302.

Slomkowski, C., \& Dunn, J. (1996). Young children's understanding of other people's beliefs and feelings and their connected communication with friends. Developmental Psychology, 32, 442-447.

Sousa, C., Okamoto, S., \& Matsuzawa, T. (2003). Behavioural development in a matching-to-sample task and token use by an infant chimpanzee reared by his mother. Animal Cognition, 6, 259-267.

Spector, P. E. (1981). Research design. London: Sage.

Sperber, D., \& Hirschfeld, L. (2004). The cognitive foundations of cultural stability and diversity. Trends in Cognitive Sciences, 8, 40-46.

Stearns, S. (1992). Evolution of life histories. Oxford, England: Oxford University Press.

Stearns, S., \& Hoekstra, R. (2000). Evolution: An introduction. Oxford, England: Oxford University Press.

Tang, Y., Zhang, W., Chen, K., Feng, S., Ji, Y., Shen, J., et al. (2006). Arithmetic processing in the brain shaped by cultures. Proceedings of the National Academy of Sciences, USA, 103, 10775-10780.

Thomas, D., Franks, D., \& Calonico, J. (1972). Role-taking and power in social psychology. American Sociological Review, 37, 605-614.

Tinbergen, N. (1951). The study of instinct. Oxford, England: Oxford University Press.

Tomasello, M. (1996). Do apes ape? In B. Galef \& C. Heyes (Eds.), Social learning in animals: The roots of culture (pp. 319-346). New York: Academic Press.

Tomasello, M. (1998). Uniquely primate, uniquely human. Developmental Science, 1, 1-30.

Tomasello, M. (1999). The cultural origin of human cognition. Cambridge, MA: Harvard University Press.

Tomasello, M., \& Call, J. (1997). Primate cognition. Oxford, England: Oxford University Press.

Tomasello, M., Carpenter, M., Call, J., Behne, T., \& Moll, H. (2005). Understanding and sharing intentions: The origins of cultural cognition. Behavioral and Brain Sciences, 28, 675-691.

Tomasello, M., Kruger, A., \& Ratner, H. (1993). Cultural learning. Behavioral and Brain Sciences, 16, 450-488.

Tomonaga, M. (1998). Perception of shape from shading in chimpanzees (Pan troglodytes) and humans (Homo sapiens). Animal Cognition, 1, 25-35.

Tooby, J., \& Cosmides, L. (1988). The evolution of war and its cognitive foundations. Proceedings of the Institute for Evolutionary Studies, 88, $1-15$.

Trivers, R. L. (1971). The evolution of reciprocal altruism. Quarterly Review of Biology, 46, 35-57.
Van de Bos, R. (1999). Reflections on self-recognition in nonhuman primates. Animal Behaviour, 58, F1-F9.

Vinden, P. (1996). Junin Quechua children's understanding of mind. Child Development, 67, 1707-1716.

Vinden, P. (1999). Children's understanding of mind and emotion: A multi-culture study. Cognition and Emotion, 13, 19-48.

Wagner, G., Chiu, C., \& Laubichler, M. (2000). Developmental evolution as a mechanistic science: The inference from developmental mechanisms to evolutionary processes. American Zoologist, 40, 819-831.

Warneken, F., Chen, F., \& Tomasello, M. (2006). Cooperative activities in young children and chimpanzees. Child Development, 77, 640-663.

Warneken, F., \& Tomasello, M. (2006, March 3). Altruistic helping in human infants and young chimpanzees. Science, 311, 1301-1303.

Wassmann, J., \& Dasen, P. (1998). Balinese spatial orientation: Some empirical evidence of moderate linguistic relativity. Journal of the Royal Anthropological Institute, 4, 689-711.

Wellman, H., Cross, D., \& Watson, J. (2001). Meta-analysis of theory of mind development: The truth about false-belief. Child Development, 72, 655-684.

West-Eberhard, M. (2003). Developmental plasticity and evolution. Oxford, England: Oxford University Press.

Whiten, A. (1996). When does smart behaviour-reading become mindreading? In P. Carruthers \& P. Smith (Eds.), Theories of theories of mind (pp. 277-292). Cambridge, England: Cambridge University Press.

Whiten, A. (2000). Chimpanzee cognition and the question of mental re-representation. In D. Sperber (Ed.), Metarepresentations: A multidisciplinary perspective (pp. 1-29). Oxford, England: Oxford University Press.

Whiten, A., Goodall, J., McGrew, W., Nishida, T., Reynolds, V., Sugiyama, Y., et al. (1999, June 17). Cultures in chimpanzee. Nature, 399, $682-685$.

Whiten, A., Goodall, J., McGrew, W., Nishida, T., Reynolds, V., Sugiyama, Y., et al. (2001). Charting cultural variations in chimpanzee. Behaviour, 138, 1489-1525.

Williams, G. (1966). Adaptation and natural selection: A critique of some evolutionary thought. Princeton, NJ: Princeton University Press.

Wilson, E. O. (1975). Sociobiology. Cambridge, MA: Harvard University Press.

Wimmer, H., Hogrefe, G., \& Perner, J. (1988). Children's understanding of informational access as source of knowledge. Child Development, 59, $386-396$

Wolfle, D., \& Wolfle, H. (1939). The development of cooperative behavior in monkeys and young children. The Journal of Genetic Psychology, 55, 137-175.

Wrangham, R. W., McGrew, F., de Waal, F., \& Heltne, P. (1994). Chimpanzees cultures. Cambridge, MA: Harvard University Press.

Zaslavsky, C. (1973). Africa counts: Number and pattern in African culture. Chicago: Lawrence Hill.

Received November 28, 2006

Revision received April 4, 2007

Accepted May 3, 2007 